\title{
Clinical Investigation on Preadolescent Acne
}

\author{
Dong Hyuk Eun, Jun Young Kim, Yong Hyun Jang, Seok-Jong Lee, Weon Ju Lee \\ Department of Dermatology, School of Medicine, Kyungpook National University, Kyungpook National University Hospital, Daegu, Korea
}

\section{Dear Editor:}

Acne is the most chronic inflammatory disease, mainly occurring in teenagers and young adults with a prevalence rate of more than $85 \%{ }^{1}$. However, acne can begin in infancy or early childhood. In addition, preadolescent acne occurs from 7 to 12 years of age $\mathrm{e}^{2,3}$. Preadolescent acne has become more common recently, but only few studies have been conducted on preadolescent acne in Korea. This study aimed to investigate characteristics of preadolescent acne.

We performed a retrospective study on preadolescent acne with medical records that were collected from one elementary school in Daegu. All of the elementary school children, aged 7 to 12 years, were regularly evaluated by two dermatologists twice a year (July and December) from 2013 to 2015 as follows: July 2013 (112 boys and 96 girls among 208 elementary school children), December 2013 (114 and 95 among 209), July 2014 (113 and 97 among 210), December 2014 (115 and 97 among 212), July 2015 (98 and 98 among 196), and December 2015 (100 and 93 among 193), totaling 1,228 (652 and 576). The study protocol complied with the Declaration of Helsinki and was approved by the institutional review board of Kyungpook National University Hospital (KNUH 2017-10-016). Elementary school children with acne were clinically assessed for acne lesion count, acne grade, the site of acne lesions, and accompanying disorders.

The number of elementary school children with acne was $27(13.0 \%)$ on July 2013, 31 (14.8\%) on December 2013, $22(10.5 \%)$ on July 2014, 35 (16.5\%) on December 2014, $13(6.6 \%)$ on July 2015 , and $20(10.4 \%)$ on December 2015, totaling $148(12.1 \%)$. The prevalence of acne was higher in winter than in summer. In addition, acne was more predominant in girls than in boys; among the elementary school children with acne, the number of girls was $18(66.7 \%), 19(61.3 \%), 13(59.1 \%), 18(51.4 \%), 10$ $(76.9 \%)$, and $14(70.0 \%)$, respectively. Of the 148 elementary school children with acne, 1 was at the age of 8 , 3 were at age 9, 9 were at age 10, 28 were at the age of 11 , and 81 were at age 12 (Fig. 1). Of the 148 elementary school children with acne, 78 were in grade I as per the Korean Acne Grading System (KAGS), 27 in grade II, and 17 in grade III 17 (Fig. 2). More than half of the acne lesions were on the forehead (60/148 elementary school children), and second most common site was the nose (20), followed by the cheek (17), chin (10), and others, including the buttocks (2), chest (1), and extremities (1). Of the 1,228 elementary school children, 117 had atopic diseases, including atopic dermatitis, allergic rhinitis, and asthma. Among the atopic diseases, the number of elementary school children with atopic dermatitis, allergic rhinitis, and asthmas were 59,57, and 14, respectively. Twenty-five (21.4\%) of the 117 elementary school children with atopic diseases showed acne lesions. Twelve $(20.3 \%)$ of the 59 elementary school children with atopic dermatitis, $14(24.6 \%)$ of the 57 had allergic rhinitis, and 4 $(28.6 \%)$ of 14 with asthma were accompanied by acne.

Preadolescent acne patients are prone to stressful emotions due to unfavorable changes of appearance. Therefore, early recognition and prompt initiation of therapy are important to prevent the sequelae of emotional distress and severe facial scarring. In the preadolescent period, acne may be the first sign of pubertal maturation. In addition, severity of preadolescent acne may be predictive of the

\footnotetext{
Received December 8, 2017, Revised April 6, 2018, Accepted for publication April 12, 2018
}

Corresponding author: Weon Ju Lee, Department of Dermatology, School of Medicine, Kyungpook National University, Kyungpook National University Hospital, 130 Dongdeok-ro, Jung-gu, Daegu 41944, Korea. Tel: 82-53-420-5838, Fax: 82-53-426-0770, E-mail: weonju@knu.ac.kr ORCID: https://orcid.org/0000-0001-5708-1305

This is an Open Access article distributed under the terms of the Creative Commons Attribution Non-Commercial License (http://creativecommons.org/ licenses/by-nc/4.0) which permits unrestricted non-commercial use, distribution, and reproduction in any medium, provided the original work is properly cited.

Copyright (C) The Korean Dermatological Association and The Korean Society for Investigative Dermatology 


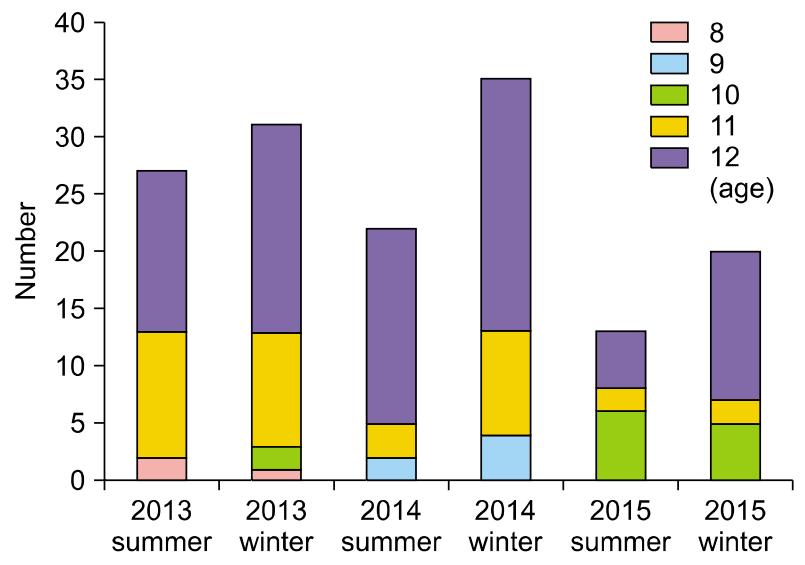

Fig. 1. The number of elementary school children with acne according to age.

status of adolescent acne. Preadolescent acne is related with an increase in sebum production and urinary excretion of androgenic steroids ${ }^{3}$. Some previous studies reported that the presence or severity of preadolescent acne in both sexes correlates to advanced pubertal maturation ${ }^{4}$. Significant elevation in dehydroepiandrosterone sulfate (DHEAS) is linked to comedonal and inflammatory acne in preadolescent girls ${ }^{5}$. In addition, severe preadolescent acne was linked to an earlier onset of menarche and higher levels of DHEAS and total and free testosterone levels as compared with mild preadolescent acne. This study suggests that acne can be a common skin disease in the preadolescent period. As expected, the prevalence of preadolescent acne in girls was approximately 1.6 times that in boys. Many studies have shown increased levels of ovarian androgens at adrenarche, and the androgens may be responsible for early-onset acne in girls ${ }^{4}$. Seasonal variation of acne is still controversial. Some studies have shown that acne is exacerbated by increased sweating, hot humidity, and comedogenic effects of sunlight during summer ${ }^{6,7}$. On the contrary, others proved ultraviolet light-induced immune suppression in the summer ${ }^{8}$. In this study, the number of elementary school children with acne was relatively higher in winter than in summer. This study showed a tendency of increased prevalence with age, like other previous reports ${ }^{9}$. The severity of preadolescent acne was mild, showing most commonly KAGS grade I. The predominant site of preadolescent acne was the T-zone, including the forehead and nose. In this study, 117 elementary school children had atopic diseases, including atopic dermatitis, allergic rhinitis, and asthma. Of 117 elementary school children, 25 had acne lesions. Some studies suggested that the appearance of acne is associated with epidermal barrier impairment in the facial skin ${ }^{10}$. However, there are several limitations to

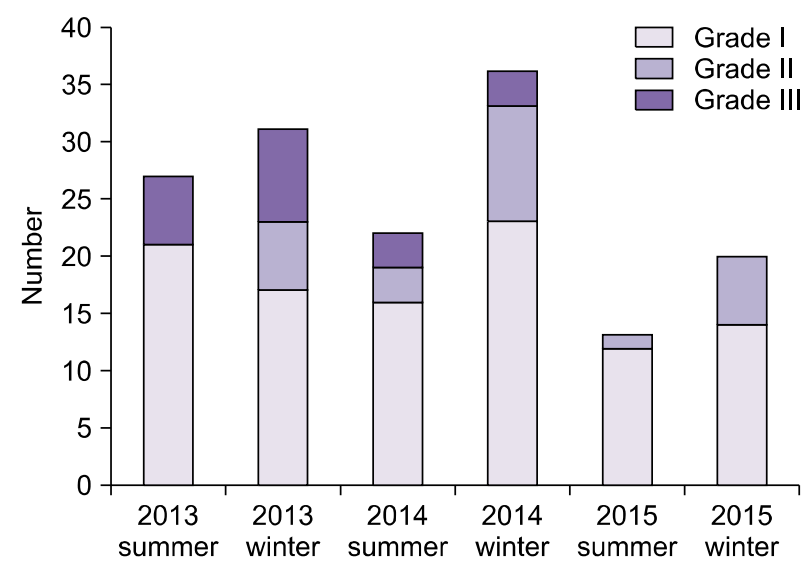

Fig. 2. The number of elementary school children with acne according to the Korean Acne Grading System.

this study because of the regular field survey for all students of the one elementary school. The clinical data including body mass index, presence of precocious puberty and family history that can effect acne were not investigated. In addition, the social and psychological impacts from the disease were not evaluated. At the subsequent study about preadolescent acne, these contents should be reflected. In conclusion, the prevalence of preadolescent acne is high. We expect that this clinical investigation would help to provide good and useful information for understanding preadolescent acne in Korea. In addition, we think that dermatologists should be alarmed to preadolescent acne and recommend elementary school children with acne to manage it properly.

\section{CONFLICTS OF INTEREST}

The authors have nothing to disclose.

\section{ORCID}

Dong Hyuk Eun, https://orcid.org/0000-0003-4044-0679 Jun Young Kim, https://orcid.org/0000-0002-2999-1018 Yong Hyun Jang, https://orcid.org/0000-0003-1706-007X Seok-Jong Lee, https://orcid.org/0000-0002-6131-632X Weon Ju Lee, https://orcid.org/0000-0001-5708-1305

\section{REFERENCES}

1. Bhate K, Williams HC. Epidemiology of acne vulgaris. Br J Dermatol 2013;168:474-485.

2. Bree AF, Siegfried EC. Acne vulgaris in preadolescent children: recommendations for evaluation. Pediatr Dermatol 2014;31:27-32.

3. Cantatore-Francis JL, Glick SA. Childhood acne: evaluation 
and management. Dermatol Ther 2006; 19:202-209.

4. Lucky AW, Biro FM, Huster GA, Leach AD, Morrison JA, Ratterman J. Acne vulgaris in premenarchal girls. An early sign of puberty associated with rising levels of dehydroepiandrosterone. Arch Dermatol 1994;130:308-314.

5. Lucky AW. A review of infantile and pediatric acne. Dermatology 1998;196:95-97.

6. Plewig G, Kligman AM. Acne and rosacea. 2nd ed. Berlin: Springer-Verlag, 1993:674-675.

7. Sardana K, Sharma RC, Sarkar R. Seasonal variation in acne vulgaris--myth or reality. J Dermatol 2002;29:484-488.

8. Hancox JG, Sheridan SC, Feldman SR, Fleischer AB Jr. Seasonal variation of dermatologic disease in the USA: a study of office visits from 1990 to 1998. Int J Dermatol 2004;43: 6-11.

9. Karciauskiene J, Valiukeviciene S, Gollnick H, Stang A. The prevalence and risk factors of adolescent acne among schoolchildren in Lithuania: a cross-sectional study. J Eur Acad Dermatol Venereol 2014;28:733-740.

10. Thiboutot D, Del Rosso JQ. Acne vulgaris and the epidermal barrier: is acne vulgaris associated with inherent epidermal abnormalities that cause impairment of barrier functions? Do any topical acne therapies alter the structural and/or functional integrity of the epidermal barrier? J Clin Aesthet Dermatol 2013;6:18-24.

\title{
Squamous Cell Carcinoma on the Fingers of Orthopedic Surgeon Induced by Occupational Radiation Exposure
}

\author{
Hee Seong Yoon, Ji Hye Heo, Si Hyub Lee, Jeonghyun Shin, Gwang Seong Choi, Ji Won Byun \\ Department of Dermatology, Inha University School of Medicine, Incheon, Korea
}

Dear Editor:

Recently, fluoroscopy is useful for diagnosis and treatment and its usage is increasing in the treatment of pain, orthopedic surgery and interventional radiology. The occupational radiation exposure of physicians is also increasing and the hand is the most exposed area. Radiodermatitis of physicians caused by occupational radiation exposure has been reported ${ }^{1}$, but there is few report of the development of squamous cell carcinoma (SCC). We describe an orthopedic surgeon with multiple SCCs on the fingers occupationally exposed to radiation.

A 49-year-old man presented with painful crusted necrotic plaques and scale widely distributed in the both fingers 2 years ago (Fig. $1 \mathrm{~A} \sim \mathrm{E}$ ). He smoked $5 \sim 6$ packs of tobacco every day. He was an orthopedic surgeon and repeatedly exposed to radiation because of frequent use of fluoroscopy. For 11 years, he performed an average of 700 cases of percutaneous vertebral augmentation and 70,000 cases of nerve block per year without radiation shielding gloves. The skin biopsy showed atypical squamous cells invading into dermis forming sheet and individual keratinization (Fig. 2). Magnetic resonance imaging of the right hand suspected bone invasion in the right index finger (Fig. $1 \mathrm{H})$. Chest computed tomography revealed slightly enlarged lymph nodes in both axilla; however, they appeared benign. We diagnosed him with SCC and pre-

Received January 5, 2018, Revised April 2, 2018, Accepted for publication April 15, 2018

Corresponding author: Ji Won Byun, Department of Dermatology, Inha University School of Medicine, 27 Inhang-ro, Jung-gu, Incheon 22332, Korea. Tel: 82-32-890-2238, Fax: 82-32-890-2236, E-mail: piggy1981@hanmail.net ORCID: https://orcid.org/0000-0003-0317-6725

This is an Open Access article distributed under the terms of the Creative Commons Attribution Non-Commercial License (http://creativecommons.org/ licenses/by-nc/4.0) which permits unrestricted non-commercial use, distribution, and reproduction in any medium, provided the original work is properly cited.

Copyright (c) The Korean Dermatological Association and The Korean Society for Investigative Dermatology 